Supplement of The Cryosphere, 10, 2043-2056, 2016

http://www.the-cryosphere.net/10/2043/2016/

doi:10.5194/tc-10-2043-2016-supplement

(C) Author(s) 2016. CC Attribution 3.0 License.

(c) (1)

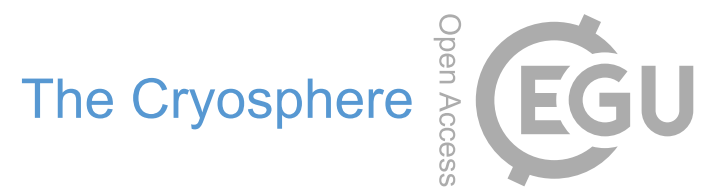

Supplement of

\title{
Grounding and calving cycle of Mertz Ice Tongue revealed by shallow Mertz Bank
}

\section{$X$. Wang et al.}

Correspondence to: Xianwei Wang (wangxianwei0304@163.com) and Xiao Cheng (xcheng@bnu.edu.cn)

The copyright of individual parts of the supplement might differ from the CC-BY 3.0 licence. 


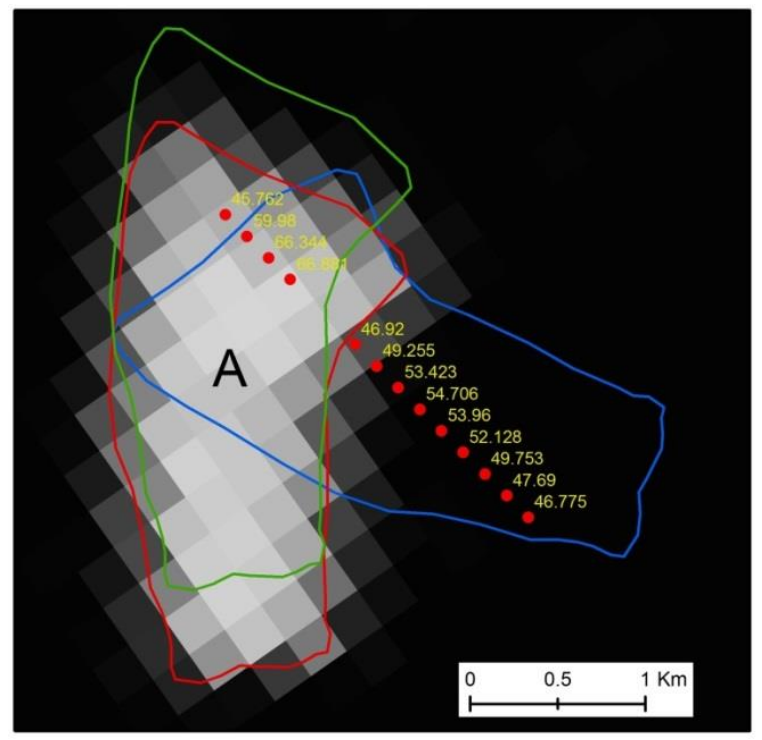

(a)

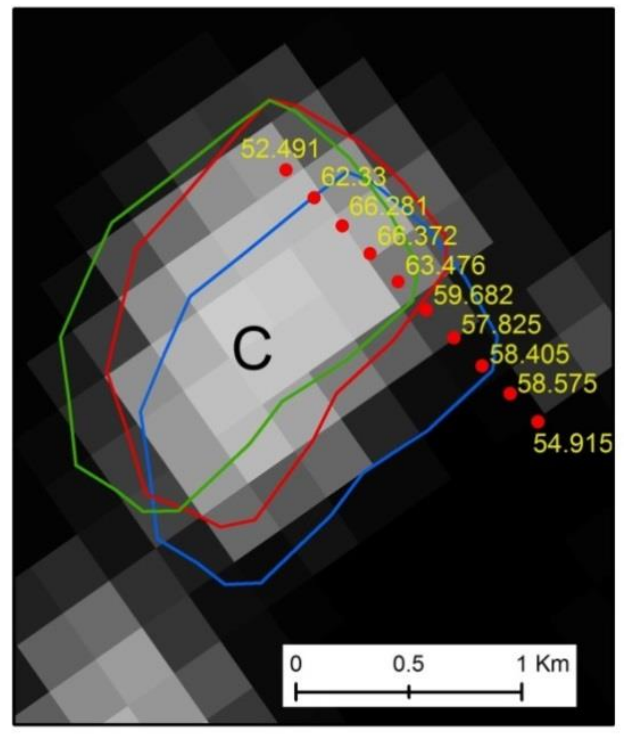

(b)

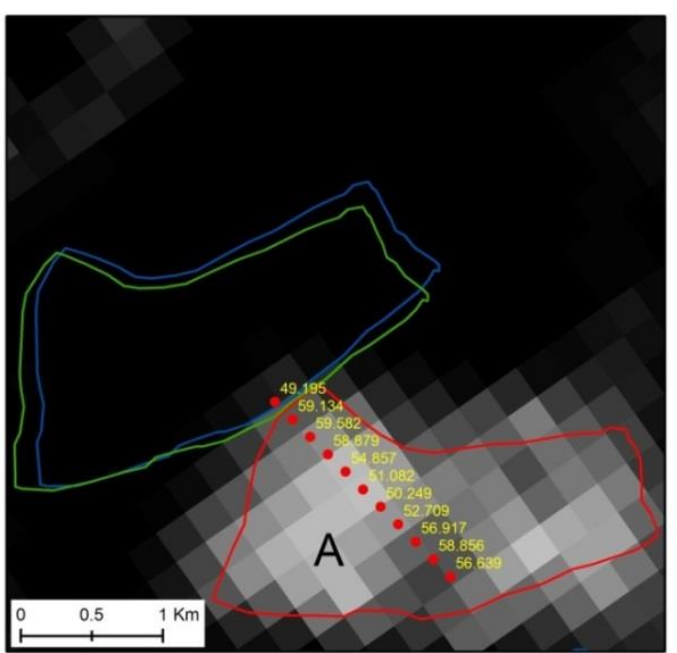

(c)

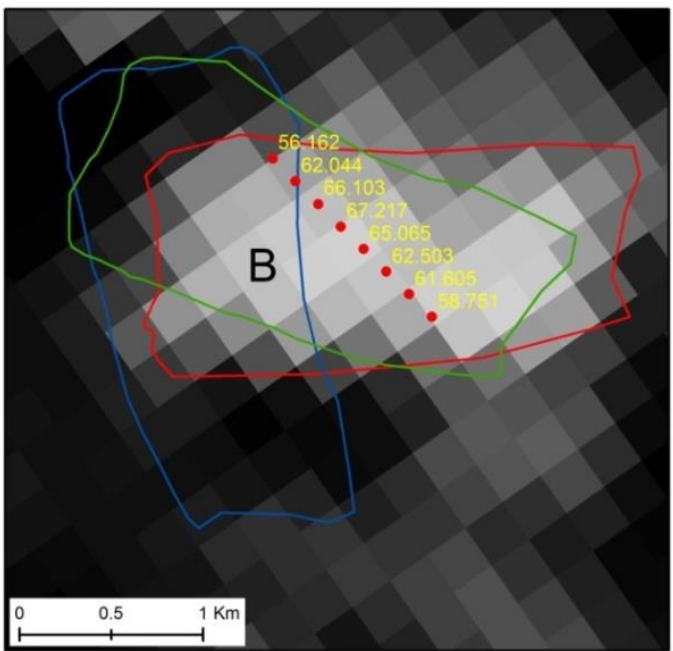

(d)

6 S-Figure 1. Freeboard extraction results from ICESat/GLAS for icebergs ' $A$ ', 'B' and ' $C$ ' in

72006 and 2008 respectively. (a) and (b) correspond to freeboard measurements from icebergs ' $A$ '

8 and 'C' respectively on February 23, 2006 (2006054), with background image from MODIS

9 captured on 2006054. (c) and (d) correspond to freeboard measurements from icebergs 'A' and 10 'B' respectively on February 18, 2008 (2008049), with background image from MODIS captured 
11 on 2008050. The locations of each iceberg in the different observation dates are indicated with

12 different colored polygons, the legend of which is the same as what is used in Fig. 4. Inside each

13 sub-figure, different icebergs are marked with 'A', 'B' and ' $\mathrm{C}$ ' respectively and iceberg 14 freeboard results in unit of meter are marked in yellow.

15 